\title{
The neurolinguistic statute of perseveration in aphasia
}

\section{O estatuto neurolinguístico da perseveração na afasia}

\author{
Silvia Saraiva Pereira Lima ${ }^{1}$, Edwiges Maria Morato²
}

\begin{abstract}
The aim of this study was to investigate perseveration in two contexts: spontaneous language and linguistic tasks. It points toward perseveration as a theoretical linguistic conception, that is, sociointeractionist. This presupposes language activity produced in an interlocutive space and it does not neglect pragmatic aspects and contextual use of language. Four patients presenting the following types of aphasia were analyzed: motor transcortical, amnestic, semantic and sensory. The results point out different aspects between pathological perseveration and perseveration as a normal expression in the process of language activity. This study might imply another theoretical perspective of language therapy to perseveration in aphasia.
\end{abstract}

Keywords: Aphasia; Fatigue; Attention; Rehabilitation; Language

\section{INTRODUCTION}

Perseveration is "the inappropriate repetition or continuation of an earlier response after a change in task requirements" $\left(\text { Neisser, } 1895^{*}\right)^{(1)}$. This term was originally applied in the description of psychosis cases and aphasia. From Ancient Times to the beginning of the Twentieth Century, perseveration was seen as a temperament function, which affected simultaneously all mental processes, when a subject came across himself emotionally disturbed. It has been analyzed in several systems of brain functions, since motor activity to a more complex one, the psychomotor, this is, motor tasks, for example.

In this point of view, perseveration is not an attribute of central nervous system but alterations of specific functions. Such statement promoted all posterior investigation about perseveration, based on analysis of some functions pointing taxonomies to perseveration. A relevant research ${ }^{(2)}$ regarding the classical perseveration studies declares that other ideas on perseveration are embedded in the modern concepts of the phenomenon. Another perspective shows that there are no systematic studies about perseveration in normal subjects. Furthermore, perseveration researches in these subjects appe-

Trabalho baseado na tese de doutorado da primeira autora, sob orientação da Profa. Dra. Edwiges Maria Morato, realizada na Faculdade de Ciências Médicas da Universidade Estadual de Campinas - UNICAMP - Campinas (SP), Brasil.

(1) Doutora, Fonoaudióloga da Unidade de Neurolinguística e Neuropsicologia do Departamento de Neurologia da Faculdade de Ciências Médicas da Universidade Estadual de Campinas - UNICAMP - Campinas (SP), Brasil.

(2) Doutora, Professora do Departamento de Linguística do Instituto de Estudos da Linguagem da Universidade Estadual de Campinas - UNICAMP - Campinas (SP), Brasil.

Endereço para correspondência: Silvia Saraiva Pereira de Lima. R. Sampaio Ferraz, 190/73, Cambuí, Campinas - SP, CEP: 13024-430. E-mail: limassp@fcm.unicamp.br

Recebido em: 23/1/2008; Aceito em: 11/11/2008 ar in comparative analysis on subjects who have had brain injury ${ }^{(3)}$.

This study analyzes the perseveration phenomenon in aphasia, which takes into consideration: "1. Language as a constitutive activity, which emerges from linguistic categories (syntactic, semantic and pragmatic), is not a priori determined; 2. Sociointeractionist perspective of language acquisition, as a process of linguistic object construction by children, can be observed during language reconstruction process by the aphasic patient; 3 . The discursive theory that aims to analyze language in use, considering all relevant factors of a situation or context. In this outlook, language is considered being both: an individual and a collective property, as well as a cultural and historical result. This enlightens a set of meaningful sources of each language, organized according to a criterion of use interpreted by reference systems where categories and relations are culturally built in"(4).

The considered taxonomy of perseveration ${ }^{(5)}$ which proposes three independent categories, which are: “(1) continuous or inappropriate repetition of a current behavior; example: the patient drawing a daisy with several loops; (2) continuous and inappropriate maintenance of a current set or framework of 'stuck-in-set' perseveration; for example, in Digit Span Backwards, the patient persisted in repeating the numbers in the present order, as in the previous task; and (3) recurrent perseveration, unintentional repetition, after cessation of a previously emitted response to a subsequent stimulus; for example, when the patient must define words: 'bed'/[lay on]; 'ship'/[lay on, no ship, bed]; 'winter'/[winter, summer, winter, no]; 'breakfast'/[breakfast, bed, bacon]”(5).

\footnotetext{
*Neisser A. Krankenvorstellung (Fall von 'asymbolie'). Allgemeine Zeitschrift Für Psychiatrie. 1895;51:1016-21. apud Moses MS, Nickels LA, Sheard C. Chips, cheeks and carols: a review of recurrent perseveration in speech production. Aphasiology. 2007;21(10/11):960-74.
} 
These authors ${ }^{(5)}$ explain that recurrent perseveration can be either immediate or delayed. In the recurrent type, the deficit process involves a failure of the usual inhibition of memory traces. In the suck-in-set type, the process involves a breakdown in executive functioning so that actions become dissociated from intent. The continuous type of perseveration involves a disturbance in motor output characterized by post-facilitation of motor impulses ${ }^{(5)}$.

\section{PRESENTATION OF THE CLINICAL CASES}

Our research is a qualitative analysis of multiple aphasic cases in agreement with perseveration taxonomy ${ }^{(5)}$ and the perseveration concept ${ }^{(6)}$, once they are complementary. In order to obtain the linguistic corpus, it was registered speech activity of the subjects in one session and in a period maximum of 60 minutes. This research (number of stand: 329/2001), was developed with the agreement of the Ethical Research Committee of the Faculty of Medical Sciences, Universidade Estadual de Campinas, according to the Code of Ethics of the World Medical Association (Declaration of Helsinki).

Four Brazilian patients, three male (EF, 72, lawyer; SL, 58 , economist; AP, 52, school bus driver, $8^{\text {th }}$ grade), examined at the Aphasia Center, and one female (SI, 63, from Japanese origin but born in Brazil, $4^{\text {th }}$ grade), attended at the Unity of Neuropsychology and Neurolinguistic (Department of Neurology, Faculty of Medical Sciences, Universidade Estadual de Campinas), were subjects to this study. They had the following neuropsychological diagnosis: a) EF, suffered, in 12.22.1988, a cerebral vascular accident in the middle cerebral artery in the left hemisphere, presenting hemiplegia to the right and transcortical motor aphasia; b) SL suffered, in 11.3.2001, a cerebral vascular accident in the middle cerebral artery in the left hemisphere, presenting hemiparesis to the right and amnestic aphasia; c) SI suffered, in 12.5.1988, a cerebral vascular accident in the frontoparietal region in the left hemisphere, presenting hemiparesis to the right and semantic aphasia; d) AP, in 4.10.2002, was operated due to an arteriovenous malformation bleeding of the middle cerebral artery in the left hemisphere, presenting hemiparesis to the right, homonymous hemianopsia to the right and sensory aphasia. They did not present deficit in Digit Repetition. Patient EF was evaluated in 3.24.2003; SL, in 6.23.2003; SI, in 12.4.2003; and AP, in 6.18.2003. The neurolinguistic examination was obtained using the Montreal Protocol - Toulouse Examination of Aphasia, Initial Standard Module, Alpha Version ${ }^{(7)}$. This protocol also involves spontaneous language with questions related to the individuals' histories of life and language tasks (Table 1).

Three perseveration types ${ }^{(5)}$ were found in transcortical motor aphasia (EF): continuous, recurrent and stuck-in-set. In amnestic aphasia (SL), continuous perseveration type was located. In sensory aphasia (AP), continuous and stuck-in-set, with predominance of recurrent perseveration was observed. In semantic aphasia (SI), there was a recurrent perseveration type. In relation to this patient, only recurrent perseveration in an oral and writing production was noticed, such as in phrase copying (Figure 1). In spontaneous language, there was occurrence of continuous perseveration type and just only one patient (SL) presented amnestic aphasia. Therefore, continuous and phonemic carry-over** perseveration was found in linguistic task.

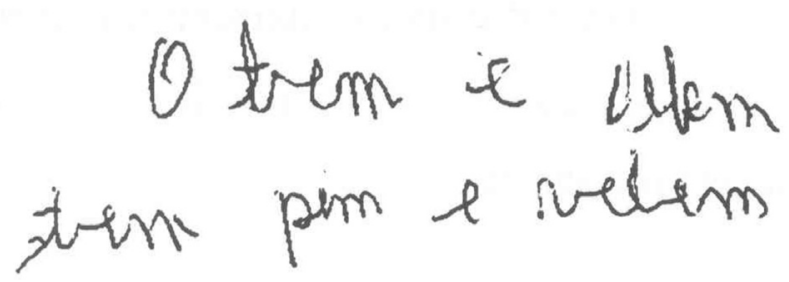

Figure 1. The recurrent perseveration type in patient SI's phrase copying

Fatigue and/or catastrophic reaction on patient with semantic aphasia were not observed. Recurrent and continuous types outline the relation between catastrophic reaction and/ or fatigue on patients with transcortical motor aphasia, amnestic and sensory aphasias. Patients with transcortical motor aphasia (SL), sensory (AP) and semantic aphasia (SI) did not persevere in spontaneous language. On the other hand, all of them perseverated in the following linguistic tasks: a) reading aloud, word repetition, figure naming (EF/transcortical motor aphasia); b) reading aloud, picture naming (SL/amnestic aphasia); c) writing, picture naming (SI/semantic aphasia); d)

Table 1. Results of the language tasks

\begin{tabular}{|c|c|c|c|c|}
\hline Task & $\begin{array}{c}\text { Transcortical } \\
\text { motor }\end{array}$ & Amnestic & Semantic & Sensory \\
\hline \multicolumn{5}{|l|}{ Oral comprehension } \\
\hline (figure recognition - simple and complex) & 3 & 1 & 3 & 3 \\
\hline Language writing comprehension (word and phrase associations - simple and complex) & 1 & 1 & 3 & 3 \\
\hline Copy (one simple phrase) & 1 & 1 & 3 & 2 \\
\hline Dictation of words and phrases (simple and complex) & 3 & 1 & 0 & 0 \\
\hline Reading aloud (words and phrases - simple and complex) & 3 & 3 & 3 & 0 \\
\hline Phrases repetition (words and phrases - simple and complex) & 3 & 3 & 3 & 2 \\
\hline Picture naming & 3 & 3 & 3 & 3 \\
\hline
\end{tabular}

Legend: 1 = Correct response; 2 = Incorrect response; 3 = Correct and incorrect response

**Although phonemic carry-over does not belong to this classification ${ }^{(5)}$, there was the occurrence of this perseveration type. 
oral/writing comprehension, oral lecture, phrases and word repetition, picture naming (AP/sensory aphasia).

\section{DISCUSSION}

Two theoretical perspectives are assumed in this study. The first one considers, in the context of evaluation, the relation between the individual with the environment. Thus, a stress situation can lead the subject, when resenting his incapacity in face of a specific task, to a catastrophic reaction. The second one $^{(7)}$ takes into account language evaluation in the metalinguistic context.

In this perspective, linguistic interpretation in the same language demands other signs of this language. This configures an essential metalinguistic operation in language acquisition and in its functioning. For example, when someone wants to be sure about what has just been said to understand the dialogue, he or she asks: "What do you mean?"(8). This author also explains that aphasic patients with selection disorder depend strongly on the situation context to speak. These patients are incapable of answering to a real or imaginary interlocutor, when they imagine themselves being the ones addressed of the message ${ }^{(8)}$.

There are three activities that can be produced with language: linguistic, epilinguistic and metalinguistic ones. The first one refers to language use in an interlocutive process; the second puts in evidence the reflexive exercise on language functioning; and the third one refers to systematization and description of language through a group of linguistic elements to speak about language ${ }^{(8)}$.

Language regulative function presents 'structural and functional differences' between external e internal languages. Still, there are two fundamental aspects considered in regulative function, the way how the subject acts with the language, and how he thinks about the language ${ }^{(9)}$. However, linguistic and epilinguistic activities (language and epilanguage) are two important process of language activity, one more conscious and the other more unaware. The interlocution as well as epilinguistic and metalinguistic activities are the most evident and regulative place of language action about other cognitive processes and sense relations. There is no possibility of a rigid criterion to separate actions with the language from actions about the language ${ }^{(9)}$.

Therefore, some relevant perseveration, among others along the examination, was selected to introduce them in the present discussion.

Literature outlines the different processes in which perseveration is produced. Some authors ${ }^{(10)}$ claim that perseveration is keenly attributed to naming tasks. Many of persevering responses found in others studies could be considered semantic paraphasia ${ }^{(11)}$. Perseveration cannot be a lexical access disorder mediated by naming tasks because other tasks, as word repetitions and oral reading, required also lexical access and probably signalized different routes to perseveration ${ }^{(12)}$. Other study ${ }^{(1)}$ indicates that some persevering errors patterns, as total perseveration and blended perseveration (related or not to the target) can arise at various processing levels as a result of underling language impairment in aphasia. In this metalin- guistic perspective, taxonomies ${ }^{(5,10)}$ emerge from perseveration in aphasia studies.

Several times, among the analyzed patients, paraphasias were detected, in naming figure tasks. Patient AP with sensory aphasia said $[p E E) U] /$ bread instead of $([\mathrm{m} E) U]^{\prime} /$ hand; he committed a phonemic paraphasia and then started to persevere in this new word $[p E E) U] /$ bread along other tasks. However, this phonemic paraphasia acquires semantic relations in face of other figures presented altogether, as bed, shovel, knife, bowl and cow. In this situation, AP said "...of bread", which means he produced a periphrasis "fork that cuts the bread" with recurrent perseveration in the word "bread".

It is also important to remind about the similitude and repetition of figures and words in the test adopted in this study, probably that could influence the appearance of persevered words. This reinforces the idea that it must reflect simultaneously a linguistic theory, which explains the nature of perseveration process, as an integrant part of linguistic activity and not only a classification, which describes it according to a modular aspect of lexical, phonemic and/or semantic representation.

For example, when patient AP, with sensory aphasia, produces recurrent perseveration in the word "girl", he elaborates its meaning: "The girl playing... he loves her". What would have propitiated this? Probably the figure "boy and girl playing"; "He loves him"; it is a playing affective relation, marked in the language development. Children play, like each other, fight, etc. This behavior seems to be that paraphasias delineate another meaning that permeates re-elaboration.

In patient $\mathrm{AP}$, an unusual response with recurrent type of perseveration in almost the whole enouncement was also perceived: when he associates the word "tin" to the figure, he answers: "[(incomprehensible), horse of car, car of car, truck, isn't it? cat (incomprehensible) so cat is of ca uck (truck) [it's hard I wish uck(truck) I wish to cure right away this part]". A strong rupture in his statement marked by a persevering response was observed, possibly mediated by fatigue. In this way, it is impossible for this patient to access new stimulus when most of these were already pronounced many times and in several linguistic contexts.

Another linguistic task established in the literature about perseveration analyzes verbal fluency, whose interpretation points to a deficit that can accent the pathological aspect of perseveration. Thus, there is an author's ${ }^{(6)}$ observation, when he asks to her aphasic patient why she said the animal's names in that semantic category: a pole bear, a brown bear, a lion, a tiger; for which she answered they were the first animals she saw when she entered the zoo of her city. This example denotes a conception of language as an activity that considers individual and collective experience, built in the interlocution space, which is constitutive of the subject. Epilinguistic is of fundamental importance when concerning the question about perseveration in aphasia, found in patients AP and SI, marked by pauses, (re)elaborations, self corrections. This dynamics composes a fluid language activity and presupposes a silent pause mediating the structured and immanent mental cognitive process, not fixed in the language activity properly. It is a regulative function activity exercised by language ${ }^{(9)}$. 
Hence, in this study, perseveration does not always configure a pathological response.

Sometimes, an adjusted behavior is intermediated by persevering productions. When naming [viol(E)U]/guitar, patient SL with amnestic aphasia said: "[vi(E)UlinU (violE)U + violinU/guitar + violin) voli, e/and [vi(E)U]... vi, vi, vo, ah, ...ah! Read another one! ]". In this example, another form of perseveration was also found, this is, phonemic carry-over ${ }^{(10)}$, where lexical access is marked by the phoneme $/ \mathrm{v} /$, in both Portuguese words [viol(E)U]/guitar and [violinU] /violin.

A self criticism in SL, a patient with semantic aphasia, was perceived, in view of recurrent perseveration, when she associated the phrase "The dog plays" [o kaSorU bRink[E] to the corresponding figures among others ("The dog is sleeping"; "the cat jumps"; "the cat is sleeping"). This patient said almost syllabizing: "[the, the... the... do (dog) barks! No! Shines! o, o, o, o, o, o, do... barks! No!]". Later, in the same task, when she should have read "The truck goes down" and discriminated it among the figures "The truck goes up"; "The truck goes down", she said whispering: "do... dog shines, no!... Barks, no is... now I don't know". She committed a verbal paraphasia and then perseverated in the word [bri' $[\mathrm{E}] /$ shines, when she should have said [brink[E]/plays.

Another author ${ }^{(13)}$ discuss about perseveration awareness. For him, "Some jargon-aphasics are sick individuals that prefer an even aberrant speech to silence. In the lack of other manners, he makes use of a paragrammatical language with many paraphasias and perseveration, agglutinations and neologisms; the sick breaks the restrictions that sickness has imposed to his verbal expression [...]. It is possible that he is aware of his language mistakes, but he is incapable of self correction. Thus, he speaks abundantly in order not be interrupted by a solicitation of explanation and clarification' and in 'jargonaphasics, anosognosia must constitute a defense mechanism, an adaptation to stress difficulty"(13).

Nevertheless, perseveration does not suggest unawareness in our patients. On the contrary, sometimes it indicates an epilinguistic direction when the patient appropriates himself of perseveration. As it has already been explained, in AP, who presents sensory aphasia, segments of jargon and light logorrhea, the word "cat", many times perseverated, showed a conscious response. When AP reads "garbage can", among five figures disposed together in a card, he says: "Cat, I have already said that". This probably means that this perseverating condition permeates the possibility to avoid a catastrophic reaction.

At his turn, EF, with severe transcortical motor aphasia, in the impossibility to attempt the target-word, goes sometimes on persevering, extenuated by the "stress condition" and by the difficulty that the task imposes itself to him. However, in this case, perseveration does not emerge as a reaction symptom to avoid catastrophic reaction and consequently a non-pathological symptom ${ }^{(6)}$. It is a catastrophic reaction it- self, when naming the last figure at the end of the test. Patient EF begins to sweat, expressing his own astonishment in face of his impossibility of goal-word access. When nominating "moustache/(cat)", EF says: "[Yes...Our Lady! Tail, tail...Our La!...Tail! No, no, tail! (laughs) yes...Our Lady! Tail, tail!!". This perseveration is also marked by self-criticism.

In this study, other aspects might be imbricated on aphasic patients' performance in their new state of life, the psychoemotional matter and the subject's life history (work, family, etc...) important issues that demand other studies.

Once perseveration, in this study, is considered as a nonpathological reaction symptom to avoid catastrophic reaction, the predominance of epilinguistic routes means that imbrications are mostly marked between paraphasia and perseveration produced by these patients. Thus, two questions are set: Could paraphasia in aphasia mediated by epilinguistic route (pause, repetition, lapses, self correction etc.) be a symptom to avoid less production of pathological perseveration in aphasia? Could paraphasia also be a symptom to avoid catastrophic reaction, given the absence of this symptom on patients with semantic and sensory aphasia?

At the end of this discussion, the following statement has to be taken into consideration: "Defining a symptom it is not necessarily the same as to understand what perseveration is. Thinking about a common root does not imply that the underlying mechanism is the same in all cases"(14). In this way, what can we think about the patient with aphasia if we do not consider that the subject is (re)constructed in the historical, social, cultural, individual spaces? In spite of the positive results of the aphasia perseveration treatment pointed in literature ${ }^{(15)}$, a review ${ }^{(1)}$ demonstrates that, "rather than treating perseveting errors in isolation, perhaps treatment programs should aim to remediate the language impairment of which perseveration is symptomatic".

\section{COMMENTS}

An essential metalinguistic activity, such as linguistic tasks, when isolated, excludes other possible routes of language activity, as seen in perseveration literature. When compared to spontaneous language, several instances of language activity are analyzed in these four patients with different types of aphasia. This casts doubt on the idea of perseveration as a "phenomenon" largely pointed in aphasia literature. In this study, it is rather reintroduce perseveration as a constitutive and integrant response of language activity. Sometimes, it is present in normal activity, as spontaneous language. More predominantly, it is produced in metalinguistic contexts, which reveals a response not always pathological. In this aspect, there is a question to be established: Does traditional metalinguistic perspective of investigation introduce perseveration as a subproduct? This study implies another theoretical perspective for perseveration in aphasia. 


\section{RESUMO}

O propósito deste estudo foi investigar a perseveração em dois contextos: linguagem espontânea e tarefas linguísticas. Esta pesquisa aponta para a perseveração como sendo uma concepção teórico-linguística, qual seja, sociointeracionista. Isto abrange atividade linguística produzida em um espaço interlocutivo e não negligencia aspectos pragmáticos e o uso contextual da língua. Quatro pacientes, apresentando os seguintes tipos de afasia, foram analisados: transcortical motora, amnéstica, semântica e sensorial. Os resultados apontam para diferentes aspectos entre perseveração patológica e perseveração, como expressão normal do processo de atividade de linguagem. Este estudo poderá implicar outra perspectiva teórica de terapia de linguagem na afasia.

Descritores: Afasia; Fadiga; Atenção; Reabilitação; Linguagem

\section{REFERENCES}

1. Moses MS, Nickels LA, Sheard C. Chips, cheeks and carols: a review of recurrent perseveration in speech production. Aphasiology. 2007;21(10/11):960-74.

2. Stark J. A review of classical accounts of verbal perseveration and their modern-"1day relevance. Aphasiology. 2007;21(10/11):928-59.

3. Ramage A, Bayles K, Helm-Estabrooks N, Cruz R. Frequency of perseveration in normal subjects. Brain Lang. 1999;66(3):329-40.

4. Coudry MIH, Morato EM. A ação reguladora da interlocução e de operações epilinguísticas sobre objetos linguísticos. Cad Estud Ling. 1988;2(5):117-35.

5. Sandson J, Albert ML. Varieties of perseveration. Neuropsychologia. 1984;22(6):715-32.

6. Goldstein K. Problem of origin of symptoms in brain damage. In: Goldstein K. Language and language disturbances: aphasic symptom complexes and their significance for medicine and theory of language. New York: Grune \& Stratton; 1948. p. 1-20.

7. Cabral LS, Parente MAMP. Protocolo Montréal-Toulouse; Exame de Afasia. Modulo Standard Inicial. Versão Alpha. 1981.
8. Jakobson R. Linguística e comunicação. In: Jakobson R. Dois aspectos da linguagem e dois tipos de afasia. São Paulo: Cultrix; 1969. p. 3462.

9. Morato EM. Linguagem e cognição: as reflexões de L. S. Vygotsky sobre a ação reguladora da linguagem. São Paulo: Plexus; 1996.

10. Santo Pietro MJ, Rigrodsky S. Patterns of oral-verbal perseveration in adult aphasics. Brain Lang. 1986;29(1):1-17.

11. Papagno C, Basso A. Perseveration in two aphasic patients. Cortex. 1996;32(1):67-82.

12. Hirsh KW. Perseveration and activation in aphasic speech production. Cogn Neuropsychol. 1998;15(4):377-88.

13. Lebrun Y. Afasia e anosognosia. In: Lebrun Y. Tratado de afasia. São Paulo: Panamed; 1983. p. 23-32.

14. Basso A. Perseveration or the Tower of Babel. Semin Speech Lang. 2004;25(4):375-89.

15. Helm-Estabrooks N, Emery P, Albert ML. Treatment of aphasic perseveration (TAP) program. A new approach to aphasia therapy. Arch Neurol. 1987;44(12):1253-5. 